\title{
EFSUMB Position Paper: Recommendations for Gastrointestinal Ultrasound (GIUS) in Acute Appendicitis and Diverticulitis
}

\section{EFSUMB-Positionspapier: Empfehlungen für den gastrointestinalen Ultraschall (GIUS) bei akuter Appendizitis und Divertikulitis}

Authors

Klaus Dirks ${ }^{1}$, Emma Calabrese ${ }^{2}$, Christoph F. Dietrich ${ }^{3}$, Odd Helge Gilja ${ }^{4}$, Trygve Hausken ${ }^{5}$, Antony Higginson ${ }^{6}$, Alois Hollerweger ${ }^{7}$, Giovanni Maconi ${ }^{8}$, Christian Maaser ${ }^{9}$, Dieter Nuernberg ${ }^{10}$, Kim Nylund ${ }^{11}$, Nadia Pallotta ${ }^{12}$, Tomas Ripolles $^{13}$, Laura Romanini ${ }^{14}$, Adrian Saftoiu ${ }^{15}$, Carla Serra ${ }^{16}$, Matthias Wüstner ${ }^{17}$, Ioan Sporea ${ }^{18}$

Affiliations

1 Gastroenterology and Internal Medicine, Rems-Murr-Klinikum Winnenden, Germany

2 Gastroenterology Unit, Department of Systems Medicine, University of Rome Tor Vergata, Roma, Italy

3 Medizinische Klinik 2, Caritas-Krankenhaus, Bad Mergentheim, Germany

4 Haukeland-University-Hospital, National Centre for Ultrasound in Gastroenterology, Bergen, Norway

5 Department of Medicine, Haukeland-University-Hospital, Bergen, Norway

6 Department of Radiology, Queen-Alexandra-Hospital, Portsmouth Hospitals NHS Trust, Portsmouth, United Kingdom of Great Britain and Northern Ireland

7 Radiologie und Nuklearmedizin, KH Barmherzige Brüder, Salzburg, Austria

8 Gastroenterology Unit, Department of Biomedical and Clinical Sciences, “L. Sacco” University-Hospital, “L. Sacco” University-Hospital, Milan, Italy

9 Ambulanzzentrum Gastroenterologie, Klinikum Lüneburg, Germany

10 Gastroenteroloy, Medical School Brandenburg Theodor Fontane, Neuruppin, Germany

11 Gastroenterology, Haukeland-University-Hospital, Bergen, Norway

12 Department of Internal Medicine and Medical Specialties, Sapienza University of Rome, Roma, Italy

13 Radiology, Hospital Universitario Doctor Peset, Valencia, Spain

14 Dept. of Radiology, Radiologia 1, Spedali Civili di Brescia, Italy

15 Research Center of Gastroenterology and Hepatology, University of Medicine and Pharmacy of Craiova, Romania

16 Department of Digestive System, Sant'Orsola-MalpighiHospital and University of Bologna, Italy

17 Zentrale interdisziplinäre Sonografie, Brüderkrankenhaus, Trier, Germany

18 Gastroenterology, University of Medicine and Pharmacy Timisoara, Romania
Key words

appendicitis, diverticulitis, guideline, ultrasound, gastrointestinal tract

received 10.09 .2018

accepted 03.12 .2018

Bibliography

DOI https://doi.org/10.1055/a-0824-6952

Published online: January 7, 2019

Ultraschall in Med 2019; 40: 163-175

(c) Georg Thieme Verlag KG, Stuttgart · New York

ISSN 0172-4614

Correspondence

Klaus Dirks

Gastroenterologie und Innere Medizin, Rems-Murr-Klinikum Winnenden, Am Jakobsweg 1, 71364 Winnenden, Germany Tel.: ++ 49/7195/59139322

klaus.dirks@rems-murr-kliniken.de

\section{ABSTRACT}

An interdisciplinary task force of European experts summarizes the value of gastrointestinal ultrasound (GIUS) in the management of acute appendicitis and diverticulitis. Based on an extensive literature review, clinical recommendations for these highly common diseases in visceral medicine are presented.

In patients with acute appendicitis, preoperative sonography has been established as a routine procedure in most European countries for medical and legal reasons. Routine sonography in these patients may reduce the rate of unnecessary surgery by half. The sensitivity, specificity, and accuracy of ultrasound reach values above $90 \%$ and are equivalent to CT and MRI. However, the high operator dependence may be a problem, for example in point-of-care ultrasound in emergency departments. Structured training programs, quality controls and standardized ultrasound reporting should be increasingly implemented.

In the case of suspected acute diverticulitis, "ultrasound first" should also be a basic element in the approach to all patients. Sonography can confirm the diagnosis and allows early risk stratification. As treatment strategies have become less ag- 
gressive and more tailored to the stage of diverticulitis, accurate staging has become increasingly important. GIUS and CT have proven to have similar sensitivity and specificity. Especially in cases of uncomplicated diverticulitis, GIUS will be the one and only imaging procedure. CT may work as a backup and has particular advantages for diverticulitis located in the distal sigmoid, inflammation deep in the small pelvis and insufficient ultrasound scanning conditions. This step-up approach (ultrasound first and CT only in case of a negative or inconclusive ultrasound result) has proven to yield the best accuracy.

\section{ZUSAMMENFASSUNG}

Im Rahmen des EFSUMB-Leitlinienprojekts zum gastrointestinalen Ultraschall (GIUS) gibt eine interdisziplinäre Arbeitsgruppe von europäischen Experten einen Überblick zum Nutzen der Sonografie bei akuter Appendizitis und Divertikulitis. Basierend auf einer umfangreichen Literaturrecherche werden klinische Empfehlungen zu diesen häufigen Erkrankungen der Viszeral-Medizin vorgestellt.

Bei Patienten mit akuter Appendizitis haben medizinische und juristische Erwägungen die präoperative Sonografie heute als Routineverfahren in den meisten europäischen Ländern fest etabliert. Die Sonografie kann hier die Rate unnötiger Opera- tion halbieren. Sensitivität, Spezifität und Genauigkeit des UItraschalls erreichen Werte von über $90 \%$ und entsprechen CT oder MRT. Eine hohe Untersucherabhängigkeit kann jedoch problematisch sein, beispielsweise beim bettseitigen Ultraschall in der Notaufnahme oder Praxis. Strukturierte Trainingsprogramme, Qualitätskontrollen und ein standardisierter Befundbericht sollten deshalb Einzug in den klinischen Alltag finden. Auch beim Verdacht auf eine akute Divertikulitis sollte die „ultrasound first“-Strategie Anwendung finden.

Die Sonografie kann die Diagnose einer Divertikulitis bestätigen und den Schweregrad abschätzen. Da heutige Therapiestrategien weniger aggressiv und mehr auf das Stadium der Divertikulitis zugeschnitten sind, ist eine genaue Einteilung des Schweregrads immer wichtiger geworden. GIUS und CT haben hier eine ähnliche Sensitivität und Spezifität. Gerade bei unkomplizierter Divertikulitis ist die Sonografie völlig ausreichend. Das CT kann als Backup dienen und hat Vorteile bei der Divertikulitis im distalen Sigma, bei einer Entzündung tief im kleinen Becken oder bei unzureichenden Untersuchungsbedingungen. Eine solche Stufendiagnostik (Ultraschall zuerst und CT nur im Falle eines negativen oder nicht eindeutigen Befundes) hat bei der Divertikulitis die höchste Genauigkeit bewiesen.

\begin{tabular}{|c|c|}
\hline 1. & Introduction \\
\hline 2. & Acute appendicitis \\
\hline 2.1. & Prevalence and clinical implication \\
\hline 2.2. & Examination technique \\
\hline 2.3. & Sonography of uncomplicated appendicitis \\
\hline 2.4. & Sonography of complicated appendicitis \\
\hline 2.5. & Value of the different sonographic criteria \\
\hline 2.6. & False negative results \\
\hline 2.7. & False positive results \\
\hline 2.8. & Comparison of US with others imaging methods \\
\hline 2.9. & Diagnostic strategy \\
\hline 2.10. & Education and quality management \\
\hline 3. & Acute diverticulitis \\
\hline 3.1. & Prevalence and clinical spectrum of acute diverticulitis \\
\hline 3.2 . & Examination technique \\
\hline 3.3. & Classification of acute diverticulitis \\
\hline 3.4 . & Sonography in uncomplicated diverticulitis \\
\hline 3.5. & Sonography in complicated diverticulitis \\
\hline 3.6. & Unusual localizations of diverticulitis \\
\hline 3.7. & The role of US in the treatment of diverticular abcesses \\
\hline 3.8. & Comparison of GIUS with others imaging methods \\
\hline 3.9. & Diagnostic strategy \\
\hline
\end{tabular}

\section{Introduction}

In 2014 the European Federation of Societies for Ultrasound in Medicine and Biology (EFSUMB) formed a Gastrointestinal Ultrasound (GIUS) task force group to promote the use of GIUS in a clinical setting. Altogether seven "Recommendations and Guidelines for Gastrointestinal Ultrasound (GIUS)" are planned. Guidelines for examination techniques and normal findings [1] and for inflammatory bowel diseases [2] marked the kick-off last year. This paper adds recommendations for acute appendicitis and diverticulitis as highly common diseases in visceral medicine.

A team of 18 European experts in Gastrointestinal Ultrasound from Gastroenterology, Radiology and Surgery created recommendations for the use of imaging, based on an extensive literature review until May 2018. These recommendations were refined and finally voted on in an online survey. The agreement/disagreement level was scored on a five-point Likert scale as follows: $A+$ : agree; $A-$ : rather agree; I: indecisive; D-: rather disagree; $\mathrm{D}+$ : disagree. All 21 statements had broad agreement of more than $80 \%$ of the experts. The consensus levels of agreement are listed for each recommendation.

\section{Acute appendicitis}

\subsection{Prevalence and clinical implication}

Acute appendicitis is the most common surgical disease in Western countries, with a lifetime prevalence of $7-8 \%[3,4]$. In 1986, Puylaert introduced graded compression ultrasound in the workup of suspected appendicitis [5]. Beside clinical examination 
and laboratory findings, imaging has become the third component in the assessment of patients with suspected appendicitis $[6,7]$. The three main goals of the ultrasound examination are:

- Exclusion of an alternative abdominal disease.

- Confirmation of typical appendicitis or

- Ruling out of acute appendicitis, by proving a normal appendix over its entire length.

The routine use of ultrasound in suspected appendicitis halves the rate of negative appendectomies and reduces surgical complications and costs [6, $8-10]$.

Recent studies evaluated antibiotic therapy as a possible alternative in selected cases of uncomplicated appendicitis. For this, appendicitis must be verified by imaging and complicated versus uncomplicated appendicitis should be distinguished [11 - 13].

\section{STATEMENT 1}

The use of ultrasound imaging should be a routine procedure in every patient with suspected appendicitis.

Consensus levels of agreement: $A+16 / 18 ; A-2 / 18$

\section{STATEMENT 2}

Routine sonography in all patients with suspected appendicitis halves the rate of unnecessary surgery (negative laparotomy rate).

Consensus levels of agreement: $A+14 / 18 ; A-4 / 18$

\subsection{Examination technique}

One way to detect an inflamed appendix is a simple search at the point of maximum tenderness [5]. An alternative way involves systematic localization of the ascending colon, the cecal pole, the terminal ileum and the origin of the appendix, $2-3 \mathrm{~cm}$ below the medial contour of the cecum $[14,15]$. Examination is performed using the graded compression technique first described by Puylaert [5]. Gentle compression eliminates disturbing gas and reduces the distance to the pathologic process. Additions to this technique have been described, for example a left oblique body position in obese patients or an upward graded compression technique in children [16 - 19]. Ultrasound experience plays a role in the visualization of the appendix. Practical training in normal and pathological conditions is mandatory to enable adequate appendix evaluation.

\section{STATEMENT 3}

The graded compression technique should be used for visualization of the appendix.

Consensus levels of agreement: $A+18 / 18$

\section{STATEMENT 4}

Anatomical variations require a systematic examination technique for identification of the appendix.

Consensus levels of agreement: $A+17 / 18 ; A-1 / 18$

\subsection{Sonography of uncomplicated appendicitis}

Previously, acute appendicitis was diagnosed when a thickened vermiform appendix could be visualized at the point of maximum tenderness [5]. However, increasing experience and technical improvements have made it possible to demonstrate a normal appendix in more than half of adults and more than $70 \%$ of children [20-22]. Beside maximum diameter, several additional criteria that help to distinguish between an inflamed and a normal appendix have been established. These criteria are the same for children and adults [23].

\section{Primary signs of acute appendicitis}

1. Maximum outer diameter of more than $6 \mathrm{~mm}[14,17,24-30]$. A diameter between $6-8 \mathrm{~mm}$ indicates an equivocal zone of uncertainty $[27,31,32]$.

2. Maximal tenderness over the thickened appendix $[5,15,29$, 33, 34].

3. Incompressibility of the inflamed appendix $[14,17,24,25$, $28-30,35]$.

4. (Large) appendicoliths [14, 25, 26, 28, 29, 36].

5 . Hypervascularity in color Doppler in uncomplicated cases [14, 29, 37, 38].

6. Loss of stratification in gangrenous appendicitis $[25,29,30,36]$.

Secondary signs of acute appendicitis (in the surroundings)

1. Hyperechoic periappendiceal tissue $[14,15,17,24,25,29,30$, 34, 39].

2. Complex fluid collection (pericecal abscess) $[14,15,17,25$, 29, 39].

3. Mesenteric lymphadenopathy [14, 15, 25, 40, 41].

4. Periappendiceal fluid $[14,15,25]$.

\subsection{Sonography of complicated appendicitis}

Complicated appendicitis includes gangrenous appendicitis (focal or complete necrosis of the wall) as well as perforation (inducing abscess, regional peritonitis and general peritonitis). Confirmation of these complications has consequences for treatment and usually rules out conservative treatment $[13,42,43]$. There is a continuous transition from severe uncomplicated (phlegmonous) to gangrenous appendicitis.

The loss of the normally echogenic submucosal layer seems to be the best independent indicator of gangrenous appendicitis [11]. Other indicators of necrosis may be the lack of vascularization on color Doppler or an appendiceal wall enhancement defect, but these have not been sufficiently investigated [44, 45].

Signs of (sealed) perforation are extraluminal gas, localized collections of periappendiceal fluid, extraluminal appendicoliths and abscess $[14,15,24,25,39]$. 
To distinguish non-complicated from complicated appendicitis, scoring systems based on clinical and imaging features have been suggested [13, 44-46]. However, they must still be confirmed in larger studies. Other features like intraluminal appendicoliths do not implicate complicated appendicitis, but are associated with perforation and recurrence under antibiotic therapy $[42,47,48]$.

\subsection{Value of the various sonographic criteria}

In routine clinical examination, only the combination of as many different criteria as possible guarantees the best results in the validation or ruling out of acute appendicitis [14, 15, 24, 25, 29, $30,33,34,39]$. The three most important criteria in the confirmation of acute appendicitis are:

1. max. diameter of appendix $>6 \mathrm{~mm}$

2. maximum pain over the appendix

3. hyperechoic periappendiceal tissue

Free fluid, mesenteric lymphadenopathy and vascularity of the appendiceal wall on color Doppler are nonspecific signs and can be found in many other situations [14, 15, 25]. Definite exclusion of appendicitis requires visualization of the normal appendix in its entire length [29].

\section{STATEMENT 5}

A thickened appendix at the point of maximum tenderness and hyperechoic periappendiceal tissue are the most important signs of appendicitis.

Consensus levels of agreement: A+15/17; A-2/17

\subsection{False-negative results}

Non-visualization of the appendix is a problem and does not rule out acute appendicitis. The most important reason for false-negative results is inexperience in GIUS and the examination technique. In this case, an intensive search for indirect signs of appendicitis should be performed as a first step [49-51].

However, some situations are challenging even for experienced investigators: in particular when the appendix has a retrocecal or pelvic position or in very obese patients [33, $52-54]$. In these cases, adequate compression, scanning in a left lateral decubitus position of the patient and use of a convex probe may be essential to visualize the appendix [17, 52, 53]. Focal appendicitis confined to the tip has a frequency of about $5 \%$ and is another factor in misdiagnosis [25, 37]. Therefore, demonstration of the entire length of the appendix is important $[15,25,37]$.

Gas in the appendiceal wall in cases of gangrenous appendicitis may be misinterpreted as a gas-containing bowel loop [15, 55]. A perforated and completely destructed appendix in an abscess is another rare cause of a false-negative result.

\section{STATEMENT 6}

Adequate training is a precondition for sonographic diagnosis of acute appendicitis.

Consensus levels of agreement: $A+18 / 18$

\section{STATEMENT 7}

Atypical positions of the appendix are the most frequent cause of false-negative results.

Consensus levels of agreement: $A+12 / 18 ; A-4 / 18 ; 12 / 18$

\subsection{False-positive results}

Soon after introducing ultrasound as a preoperative tool, cases of “spontaneously resolving appendicitis" were observed [56, 57]. Recent research confirms mild forms of appendicitis, which resolve spontaneously or under antibiotic therapy [4, 58, 59]. Strictly speaking they are not false-positive, but rather mild courses that probably would not require surgery.

Several other pitfalls can lead to a false-positive US diagnosis of acute appendicitis:

1. Incorrect classification of the terminal ileum as an inflamed appendix [15, 60 -64].

2. Other tubular structures in the right lower abdomen simulating an inflamed appendix:

- e. g. Meckel's diverticulitis

- right-sided colonic diverticulitis

- dilated Fallopian tube

- gonadal vein thrombosis

- muscle fibers of psoas [15, 61, 62, 64]

3. Appendiceal thickening can also be produced by other conditions [65-71]:

a) Primary appendiceal thickening

- Crohn's disease: appendicular involvement is relatively frequent $(20-25 \%)$ [65-67]

- infectious enterocolitis

- cecal carcinoma $[61,66,68]$

- appendiceal tumors such as cystadenoma, mucocele or carcinoid $[61,66,69]$

b) Secondary thickening (periappendicitis in case of peritonitis)

\section{STATEMENT 8}

Systematic search for signs that suggest differential diagnoses of appendicitis should be implemented.

Consensus levels of agreement: $A+17 / 18 ; A-1 / 18$

\subsection{Comparison of US with others imaging methods}

The diagnostic accuracy of high-end ultrasound in suspected appendicitis has clearly improved over the last decades. Meanwhile the sensitivity, specificity, and accuracy of ultrasound have reached values above $90 \%$ and are equivalent to CT or MRI [72-78]. 
- Table 1 Based on clinical assessment, laboratory results, and possibly scoring results, three scenarios are common in the daily routine.

\begin{tabular}{|l|l|l|}
\hline risk of appendicitis & $\begin{array}{l}\text { Alvarado or AIR } \\
\text { points }\end{array}$ & impact of sonography \\
\hline low & $0-4$ & $\begin{array}{l}\text { visualization of the normal appendix in its full length definitively rules out appendicitis } \\
\text { complete ultrasound is helpful in finding an alternative diagnosis }\end{array}$ \\
\hline intermediate & $5-8$ & $\begin{array}{l}\text { validation of an inflamed appendix confirms the need for surgery } \\
\text { if the diagnosis remains unclear, complementary CT, MRI or serial ultrasound performed by an } \\
\text { experienced operator may be helpful }\end{array}$ \\
\hline high & $>8$ & \begin{tabular}{l} 
confirmation of acute appendicitis \\
\hline
\end{tabular} \\
\hline & & diagnosis of complications, e. g. abscess \\
\hline
\end{tabular}

However, ultrasound is a highly operator-dependent tool, and its sensitivity fluctuates greatly in the case of inexperienced operators or inadequate equipment. Institutions using US regularly have a higher sensitivity, and the sensitivity increases with an increased rate of visualization of the appendix [79-81]. In addition, patient characteristics (e.g. obesity) may influence the sensitivity of US [82].

Point-of-care ultrasonography (POCUS) is increasingly performed by emergency physicians to diagnose acute appendicitis and is available around the clock. If adequate equipment and training are provided, the results will reach accuracy nearly equal to that of ultrasound performed by radiologists, gastroenterologists and pediatricians [83-86].

Ultrasound for suspected appendicitis may be challenging among pregnant women: if the appendix can be visualized, the specificity of US is good. In equivocal cases, MRI has a higher sensitivity and is considered the method of choice in pregnant women [85, 87].

\section{STATEMENT 9}

In the hands of well-trained operators and with adequate equipment, the sensitivity and specificity of ultrasound in acute appendicitis are similar to CT and MRI.

Consensus levels of agreement: $A+15 / 18 ; A-2 / 18 ;$ I 1/18

\subsection{Diagnostic strategy}

Preoperative imaging has become routine in the workup of suspected appendicitis for both medical and legal reasons. Ultrasound is available in almost every emergency department as a point-of-care procedure 24/7 hours without delay. It is cheap, noninvasive and without ionizing radiation [88].

Based on this data, an "ultrasound first and always" strategy has proved to be reasonable in both children and adults [89 - 93]. Primary ultrasound supports the ALARA principle (radiation as low as reasonably achievable), thereby avoiding radiation exposure, especially in children and women of childbearing age $[94,95]$. Consistent use of ultrasound in right lower quadrant pain can reduce the need for additional CT or MRI imaging to a small fraction [76, 96 - 99]. Cases of inconclusive ultrasonography should lead to clinical reassessment. A second ultrasound after an observation period $[100,101]$ or a complementary MRI or CT examination should be considered.

Diagnostic scoring systems are recommended in some guidelines as a part of a diagnostic algorithm for suspected appendicitis $[87,102]$. There are several competing scores [e.g. the Alvarado Score, Pediatric Appendicitis Score (PAS), and Appendicitis Inflammatory Response score (AIR)] but these do not always perform satisfactorily. Even the cut-off values are not clear. Scores may be used for roughly estimating the likelihood, but not for proving appendicitis [103-105]. In accordance with the Dutch guidelines [92], we recommend routine use of ultrasound in all cases of suspected appendicitis and do not consider the use of scoring groups obligatory ( $\triangleright$ Table 1 ).

\section{STATEMENT 10}

In any case of suspected appendicitis, an "ultrasound first" strategy should be used in both children and adults.

Consensus levels of agreement: $A+18 / 18$

\section{STATEMENT 11}

Complementary CT or MRI should be limited to inconclusive findings and difficult conditions, e. $\mathrm{g}$. in very obese patients or in pregnant women (MRI).

Consensus levels of agreement: $A+14 / 18 ; A-3 / 18 ;$ I 2/18; D- 1/18

\subsection{Education and quality management}

In more cases than in other imaging modalities, GIUS depends on individual skills and adequate ultrasound equipment. So-called "non-diagnostic ultrasound" represents a problem especially among less experienced operators. Non-diagnostic ultrasound is caused either by borderline results (e.g. borderline thickening of the appendix to $7 \mathrm{~mm}$ ) or if the appendix could not be visualized. Non-visualization should be minimized by training and ultrasound experience $[106,107]$. If the appendix cannot be visualized, the report should include information as to whether secondary findings in the right lower abdomen were present or not [108]. 
Visualization of the appendix and especially the search for secondary sonographic features can be taught even to less experienced investigators [83, $109-112]$. A structured training program, the use of standardized ultrasound reporting templates and regular feedback enhance the accuracy of ultrasound and dramatically reduce the number of non-diagnostic ultrasound scans $[8,77,108,113-118]$. In this way, the use of CT for patients with an equivocal ultrasound result, costs and admission for observation can be reduced [114].

\section{STATEMENT 12}

Structured training programs, quality controls and the use of standardized ultrasound reporting templates should be integrated in the training of emergency physicians for point-ofcare ultrasound (POCUS) in appendicitis.

Consensus levels of agreement: $A+17 / 18 ; D+1 / 18$

\section{Acute diverticulitis}

\subsection{Prevalence and clinical spectrum of acute diverticulitis}

Colonic diverticula are a common condition, especially in elderly people in Western populations. Complications such as diverticulitis and diverticular bleeding are a frequent cause of hospital admission [119]. Acute diverticulitis occurs in approximately $5 \%$ of people with diverticula, sometimes in recurrent episodes $[120,121]$. The incidence of acute diverticulitis seems to have increased during the last years, especially in young and obese subjects [119].

For many years the diagnosis of acute diverticulitis was made clinically, by the triad of left-sided abdominal pain, fever and laboratory markers of inflammation. However, systematic evaluation revealed a high rate of incorrect diagnosis [122, 123], and additional imaging was recommended in cases of suspected diverticulitis [124-128]. Furthermore, imaging procedures enable us to differentiate uncomplicated from complicated diverticulitis. Roughly, $15 \%$ of patients have complicated disease, defined as an abscess, perforation, fistula, or stenosis [124].

\section{STATEMENT 1}

Ultrasound imaging should be a routine procedure in all patients with suspected diverticulitis.

Consensus levels of agreement: $A+17 / 18$; I 1/18

\section{STATEMENT 2}

Sonography can confirm the diagnosis of acute diverticulitis and allows early risk stratification.

Consensus levels of agreement: A+16/18; A-1/18; I 1/18
- Table 2 Classification of Diverticular Disease (CDD) 2014.
type 0 asymptomatic diverticulosis
type 1 acute uncomplicated diverticulitis
- 1a: without phlegmonous reaction
- 1b: phlegmonous reaction (colon/surroundings)
type 2 acute complicated diverticulitis
- 2a Microabscess (<1 cm)
- 2b Macroabscess
- 2c Free perforation
type 3 chronic diverticular disease
type 4 diverticular bleeding

\subsection{Examination technique}

The scanning techniques for evaluating the colon are described in detail in part 1 of the EFSUMB recommendations for GIUS [1] and in the WFUMB position papers $[117,118]$. The graded compression technique is used as described in appendicitis. The easiest way to start your search is at the point of maximum tenderness pointed out by the patient $[129,130]$. Alternatively, the sigmoid colon could be localized ventral to the left iliac artery in a cross section and from there be tracked distally and orally to the descending colon. Particularly, for the lower sigmoid, a moderately filled urinary bladder may be beneficial.

\subsection{Classification of acute diverticulitis}

Various classifications of acute and chronic diverticulitis have been published and modified during the last 55 years $[128,131]$. The first of these classifications was based on clinical and surgical findings [132]. In 1978, Hinchey's original classification [133] divided complicated diverticulitis into four stages (from local abscess to generalized fecal peritonitis). Hinchey's classification was refined and amended several times and, until today, in various modifications, it remains the basis of most classifications.

Most of the current classifications are based on CT findings [134], but, to this day, not even the use of intravenous or rectal contrast agents is standardized. Ultrasound as a "point-of-care" method that is available in almost every emergency department proved to be able to confirm and classify acute diverticulitis as well $[130,135,136]$.

In 2014, the German Society of Gastroenterology (DGVS) and the Society of Visceral Surgery (DGAV) agreed on another classification as part of the new German S2k guidelines: Classification of Diverticular Disease (CDD) [125]. This classification is not linked to a specific diagnostic preference, such as CT versus ultrasonography [137, 138]. However, all guidelines distinguish between uncomplicated and complicated diverticulitis. Complications are generally defined as abscess, perforation, fistula or stenosis [128] ( Table 2).

\subsection{Sonography in uncomplicated diverticulitis}

Uninflamed colonic diverticula can be detected as outpouchings of the colonic wall, often containing gaseous feces or fecaliths, sometimes associated with acoustic shadowing $[136,139,140]$. 
Particularly, sigmoid colon diverticulosis may be associated with slight thickening of the muscularis propria (the outer hypoechoic layer), caused by a hypertrophied circular smooth muscle.

The following three criteria allow the sonographic diagnosis of acute diverticulitis [130, 136, 139, 141]:

1. Short segmental colonic wall thickening (>5 mm).

2. Demonstration of the inflamed diverticulum in the wall-thickened area (in contrast to normal diverticula, they are often hypoechoic and are surrounded by hyperechoic fatty tissue).

3. Pericolic tissue changes (non-compressible, hyperechoic).

All three signs correlate very well with the point of maximum tenderness and can be evoked by the graded compression, with the ultrasound transducer (dynamic examination).

These criteria have been confirmed by prospective studies and two meta-analyses, providing high diagnostic accuracy, with a sensitivity and positive predictive value above $90 \%[7,135$, 142 - 145]. The diagnostic accuracy remains slightly inferior to that of CT scan, particularly in obese patients and in deeply seated lesions in the pelvis. In contrast to the United States, sonography is used as the first-line imaging modality in some European countries and most developing countries [125, 137, 146 - 149]. A stepup strategy with US as the first-line method followed by CT whenever US is inconclusive or unreliable seems to represent the most effective approach [150].

\section{STATEMENT 3}

GIUS accurately assesses acute diverticulitis by detecting short segmental colonic wall thickening (>5 mm), an inflamed diverticulum and pericolic tissue changes. Consensus levels of agreement: A+15/17; A-2/17

\section{STATEMENT 4}

GIUS should be the first-line diagnostic procedure followed by additional CT scan only in the case of inconclusive sonographic findings.

Consensus levels of agreement: $A+13 / 18 ; A-2 / 18 ; D-2 / 18$; $D+1 / 18$

\subsection{Sonography in complicated diverticulitis}

In cases of severe diverticulitis, greater thickening of the colonic wall and increasing paracolic tissue changes can be found. The typical complications of acute diverticulitis include abscess formation, fistulas, perforation and stenosis (CDD type 2).

The US morphology of diverticular abscesses varies widely: they usually appear as hypoechoic fluid collections, sometimes containing echogenic debris and gas bubbles. Hyperechoic, gascontaining abscesses are sometimes difficult to differentiate from bowel loops [151]. In unclear cases with a suspected abscess deep in the pelvis or a gas-containing abscess, additional CT should be performed.
Contrast-enhanced ultrasound (CEUS) is an accurate method for differentiating between intra-abdominal phlegmon and abscess, which both may manifest as hypoechoic masses [152]. CEUS may help to better define the size of the fluid collections and guide sonographic intervention.

Fistulas may present as hypoechoic bands with or without central gas bubbles. Fistulas can involve an adjacent bowel loop, the bladder, or the uterus [140]. Gas in the urinary bladder is an indirect sign of a sigmoid-vesical fistula.

The typical signs of perforation are gas bubbles outside the bowel loops. Contained perforations, fistulas and abscesses are characterized by air bubbles in the mesenterium or in an echo-poor fluid collection. Free peritoneal air or air bubbles in the retroperitoneal space, indicate free or retroperitoneal perforation [137, 153].

\section{STATEMENT 5}

CEUS can be used in cases of acute diverticulitis to differentiate between periintestinal phlegmon and abscess.

Consensus levels of agreement: $A+18 / 18$

\subsection{Unusual locations of diverticulitis}

Right-sided diverticulitis tends to occur in younger patients and is more frequent in the Far East. The sonographic signs are identical to those of left-sided diverticulitis and ultrasound usually allows differentiation from acute appendicitis [40, 154].

The lower sigmoid colon may be difficult to assess by transabdominal ultrasound and represents a blind spot of GIUS. Especially if the bladder is empty, lower diverticulitis in the deep pelvic region cannot be ruled out by ultrasound. As an alternative to CT or MRI imaging, additional transvaginal or transrectal ultrasound can be used $[155,156]$ but its use is not widespread.

\subsection{The role of US in the treatment of diverticular abscesses}

GIUS is a versatile tool for diagnosing paracolic abscesses in complicated diverticulitis. In some special cases, such as distant mesenteric or deep pelvic abscesses, CT has definite advantages for detection. For estimation of the real extension, CEUS may be helpful before intervention [152, 157 -159]. Microabscesses (CDD 2a) and other small abscesses (up to $3 \mathrm{~cm}$ ) can be treated successfully with antibiotics alone [125, 146, 149, 160 - 162]. For large abscesses $(>3 \mathrm{~cm}$ ) percutaneous drainage combined with antibiotics is the first choice and can significantly reduce the risk of death compared to patients undergoing acute surgery [160]. In borderline abscess, single puncture (or repeated puncture) with aspiration may be sufficient, while drainage with small catheters $(7-10 \mathrm{Ch})$ is more effective in larger abscesses [163-165]. Percutaneous drainage can be performed with ultrasound or CT guidance. If visible by sonography and technically feasible, ultrasound guidance allows real-time control of the puncture [158]. Drains are flushed several times daily and may be removed after imaging control when purulent production has ceased [149]. Injecting an ultrasound contrast agent (SonoVue, some drops diluted in saline) into the cavity through a needle or catheter can 
prove communication with the bowel lumen or display complex abscess systems [159, 166].

\section{STATEMENT 6}

Ultrasound-guided puncture/drainage is the first-line option in the therapy of abscesses larger than $3 \mathrm{~cm}$.

Consensus levels of agreement: $A+13 / 17 ; A-3 / 17 ; D-1 / 17$

\section{STATEMENT 7}

Drainage of diverticular abscesses using the trocar technique (single step) is easy to perform and is usually successful. Consensus levels of agreement: $A+16 / 17$; $A-1 / 17$

\section{STATEMENT 8}

CEUS before intervention may be helpful to demonstrate the real extension of the abscess.

Consensus levels of agreement: $A+14 / 18 ; A-1 / 18 ; / 2 / 18 ; D-1 / 18$

\subsection{Comparison of GIUS with other imaging methods}

Overall, there are a limited number of published studies reporting the direct comparison of different imaging procedures, considering the large number of affected patients. Two systematic reviews and meta-analyses demonstrated a similar accuracy of CT and ultrasound for the diagnosis of acute diverticulitis [142, 144] ( $\triangleright$ Table 3 ).

In both metanalyses and most head-to-head studies, ultrasound and $\mathrm{CT}$ were comparable with respect to the diagnosis of diverticulitis and were superior to other modalities. CT had the advantage of higher specificity and the ability to identify alternative diagnoses [144]. The role of MRI in diagnosing acute diverticulitis is not yet clear and it is not recommended as a first-line diagnostic procedure $[128,144]$. Studies comparing CT staging with intraoperative and histologic findings raise doubts as to whether CT is really the "gold standard”. In phlegmonous diverticulitis (CDD 1b; Hinchey Ila), CT resulted in overstaging in $33 \%$ of the patients [167]. Another com-

- Table 3 Comparison between GIUS, CT and MRI in two metanalyses $[142,144]$.

\begin{tabular}{|l|l|l|l|}
\hline method & $\begin{array}{l}\text { summary } \\
\text { sensitivity }\end{array}$ & $\begin{array}{l}\text { summary } \\
\text { specificity }\end{array}$ & metanalysis \\
\hline US & $92 \%$ & $90 \%$ & Lameris 2008 \\
\hline & $90 \%$ & $90 \%$ & Andeweg 2014 \\
\hline CT & $94 \%$ & $99 \%$ & Lameris 2008 \\
\hline MRI & $95 \%$ & $96 \%$ & Andeweg 2014 \\
\hline & - & - & Lameris 2008 \\
\hline & $98 \%$ & $70-78 \%$ & Andeweg 2014 \\
\hline
\end{tabular}

parison to surgery revealed considerable inaccuracy of CT in complicated diverticulitis: patients with Hinchey type III (purulent peritonitis) were understaged as Hinchey type I or II [168].

Similar studies between ultrasound and intraoperative findings are still lacking. In addition, there is only minimal data regarding ultrasound in major complications, such as distant mesenteric and pelvic abscesses or free perforation.

However, as with any artform or advanced skill, there is a large learning curve. It must be clear that little experience with GIUS inevitably yields unsatisfactory results and it has been shown that less than 500 completed examinations is insufficient $[169,170]$.

\section{STATEMENT 9}

GIUS and CT have proved to have similar sensitivity and specificity in the assessment of acute diverticulitis. Consensus levels of agreement: $A+14 / 18$; A-2/18; D- 1/18; $D+1 / 18$

\subsection{Diagnostic strategy}

Current guidelines suggest that the diagnosis in all patients with a clinical suspicion of acute diverticulitis must be confirmed by imaging on admission. As treatment strategies have become less aggressive and more tailored to the stage of diverticulitis, accurate staging of the disease has become increasingly important $[127,171,172]$. Due to the similar sensitivity and specificity of US and CT, EFSUMB recommends GIUS as the first-line imaging modality in suspected acute diverticulitis. Common advantages are bedside availability, low costs and the absence of radiation and contrast-induced nephropathy. Especially in cases of uncomplicated diverticulitis, GIUS is the only imaging method needed in acute assessment. If there is no evidence of early and significant clinical improvement, a "second look" 72 hours later may be helpful to rule out the need for intervention or surgery [170]. This second assessment can easily be done by GIUS in most cases.

CT may work as a backup after inconclusive or negative US examinations and has particular advantages for disease located in the distal sigmoid, inflammation deep in the small pelvis or insufficient US scanning conditions (e. g. in obesity). Additional $\mathrm{CT}$ may be helpful in planning drainage or immediate surgery in complicated cases. This step-up-approach (ultrasound first and $\mathrm{CT}$ only in case of a negative or inconclusive ultrasound examination) has proven to yield the best accuracy [126, 169, 173]. Ultrasound first has been incorporated in more and more European guidelines [124, 125, 128, 174]. Advantages in ultrasound technology and specific training in GIUS (e.g. in emergency medicine) will even strengthen this position in the coming years.

\section{Conflict of Interest}

Speaker honoraria, Pentax Medical Singapore Ltd Consulting/Advisory board, Mediglobe Corporation Gmbh Congress participation support, Hitachi Medical Systems UK Speaker honoraria, Abbvie, Janssen, Takeda Speaker honoraria, Bracco, Hitachi, GE, Mindray, Supersonic, Pentax, Olympus, Fuji, 
Boston Scientific, AbbVie, Falk Foundation, Novartis, Roche; Advisory Board Member, Hitachi, Mindray, Siemens; Research grant, GE Mindray, SuperSonic

Speaker honoraria, AbbVie, Bracco, Almirall, GE Healthcare, Takeda AS, Meda AS, Ferring AS, Allega

Consultant fee Bracco, GE Healthcare, Takeda and Samsung

Speaker honoraria, Abbvie, Falk Foundation, Ferring, Janssen-Cilag, MSD,

Pfizer, Takeda;

Advisory Board/Consultant fee: Abbvie, Celgene, Janssen-Cilag, MSD,

Takeda

Speaker honoraria, Abbvie, Alfa Sigma, Janssen-Cilag; Advisory Board/

Consultant fee, Allergan, Novartis, Takeda, THD

Speaker honoraria, Falk Foundation; Research grant, GE Healthcare

Speaker honoraria, Meda AS, Ferring pharmaceuticals, Takeda

Speaker honoraria, Philips, GE, Canon; Advisory Board Member,

Siemens; Congress participation support, Siemens

Speaker honoraria Bracco, Toshiba. Advisory board member Bracco.

Education support Philips. Technical consultancy Philips, BK

The following members declared no conflicts of interest:

Klaus Dirks, Trygve Hausken, Antony Higginson, Alois Holleweger, Nadia Palotta, Tomás Ripollés, Laura Romanini, Carla Serra

\section{References}

[1] Nylund K, Maconi G, Hollerweger A et al. EFSUMB Recommendations and Guidelines for Gastrointestinal Ultrasound. Ultraschall in Med 2017; 38: e1-e15. doi:10.1055/s-0042-115853

[2] Maconi G, Nylund K, Ripolles T et al. EFSUMB Recommendations and Clinical Guidelines for Intestinal Ultrasound (GIUS) in Inflammatory Bowel Diseases. Ultraschall in Med 2018; 39: 304-317. doi:10.1055/ s-0043-125329

[3] Ferris M, Quan S, Kaplan BS et al. The Global Incidence of Appendicitis: A Systematic Review of Population-based Studies. Ann Surg 2017; 266: 237 - 241. doi:10.1097/SLA.0000000000002188

[4] Bhangu A, Søreide K, Di Saverio S et al. Acute appendicitis: modern understanding of pathogenesis, diagnosis, and management. The Lancet 2015; 386: 1278 - 1287. doi:10.1016/s0140-6736(15)00275-5

[5] Puylaert JB. Acute appendicitis: US evaluation using graded compression. Radiology 1986; 158: 355 - 360. doi:10.1148/radiology.158.2.2934762

[6] Shirah BH, Shirah HA, Alhaidari WA et al. The role of preoperative graded compression ultrasound in detecting acute appendicitis and influencing the negative appendectomy rate. Abdom Radiol (NY) 2017; 42: 109 114. doi:10.1007/s00261-016-0862-0

[7] van Randen A, Lameris W, van Es HW et al. A comparison of the accuracy of ultrasound and computed tomography in common diagnoses causing acute abdominal pain. Eur Radiol 2011; 21: 1535-1545. doi:10.1007| s00330-011-2087-5

[8] Nordin AB, Sales S, Nielsen JW et al. Standardized ultrasound templates for diagnosing appendicitis reduce annual imaging costs. The Journal of surgical research 2018; 221: 77 - 83. doi:10.1016/j.jss.2017.07.002

[9] Lahaye M], Lambregts DM, Mutsaers E et al. Mandatory imaging cuts costs and reduces the rate of unnecessary surgeries in the diagnostic work-up of patients suspected of having appendicitis. Eur Radiol 2015 . 25: 1464 - 1470. doi:10.1007/s00330-014-3531-0

[10] D’Souza N, Marsden M, Bottomley S et al. Cost-effectiveness of routine imaging of suspected appendicitis. Ann R Coll Surg Engl 2018; 100: 47 51. doi:10.1308/rcsann.2017.0132

[11] Xu Y, Jeffrey RB, Chang ST et al. Sonographic Differentiation of Complicated From Uncomplicated Appendicitis: Implications for AntibioticsFirst Therapy. J Ultrasound Med 2017; 36: 269-277. doi:10.7863/ ultra.16.03109
[12] Leeuwenburgh MM, Wiezer M], Wiarda BM et al. Accuracy of MRI compared with ultrasound imaging and selective use of CT to discriminate simple from perforated appendicitis. The British journal of surgery 2014 101: e147-e155. doi:10.1002/bjs.9350

[13] Atema J], van Rossem CC, Leeuwenburgh MM et al. Scoring system to distinguish uncomplicated from complicated acute appendicitis. $\mathrm{Br}$ J Surg 2015; 102: 979-990. doi:10.1002/bjs.9835

[14] Quigley AJ, Stafrace S. Ultrasound assessment of acute appendicitis in paediatric patients: methodology and pictorial overview of findings seen. Insights Imaging 2013; 4: 741 - 751. doi:10.1007/s13244-0130275-3

[15] Hollerweger A. Acute appendicitis: sonographic evaluation. Ultraschall in Med 2006; 27: 412 -426; quiz 427-432. doi:10.1055/s-2006-927118-2

[16] Chang ST, Jeffrey RB, Olcott EW. Three-step sequential positioning algorithm during sonographic evaluation for appendicitis increases appendiceal visualization rate and reduces CT use. Am J Roentgenol 2014; 203: 1006 - 1012. doi:10.2214/Am J Roentgenol.13.12334

[17] Lee JH, Jeong YK, Park KB et al. Operator-dependent techniques for graded compression sonography to detect the appendix and diagnose acute appendicitis. Am J Roentgenol 2005; 184: 91 - 97. doi:10.2214/ ajr.184.1.01840091

[18] Schreiber-Dietrich D, Chiorean L, Cui XW et al. Particularities of Crohn's disease in pediatric patients: current status and perspectives regarding imaging modalities. Expert Rev Gastroenterol Hepatol 2015; 9: 1313 1325. doi:10.1586/17474124.2015.1083420

[19] Chiorean L, Schreiber-Dietrich D, Braden B et al. Ultrasonographic imaging of inflammatory bowel disease in pediatric patients. World J Gastroenterol 2015; 21: 5231 - 5241. doi:10.3748/wjg.v21.i17.5231

[20] Yabunaka K, Katsuda T, Sanada S et al. Sonographic appearance of the normal appendix in adults. J Ultrasound Med 2007; 26: 37 -43; quiz 45-36

[21] Hahn H, Macdonald E, Steinborn M. Sonographic detection of normal appendix in children and adolescents. Ultraschall in Med 2008; $29: 281$ 285. doi:10.1055/s-2008-1027322

[22] Rettenbacher T, Hollerweger A, Macheiner P et al. Ultrasonography of the normal vermiform appendix. Ultraschall in Med 1997; 18: 139- 142. doi:10.1055/s-2007-1000410

[23] Gongidi P, Bellah RD. Ultrasound of the pediatric appendix. Pediatr Radiol 2017; 47: 1091 - 1100. doi:10.1007/s00247-017-3928-4

[24] Rioux M. Sonographic detection of the normal and abnormal appendix. Am J Roentgenol 1992; 158: 773-778. doi:10.2214/ajr.158.4.1546592

[25] Sivit C]. Diagnosis of acute appendicitis in children: spectrum of sonographic findings. Am J Roentgenol 1993; 161: 147 - 152. doi:10.2214/ ajr.161.1.8517294

[26] Simonovsky V. Sonographic detection of normal and abnormal appendix. Clin Radiol 1999; 54: 533-539

[27] Rettenbacher T, Hollerweger A, Macheiner P et al. Outer diameter of the vermiform appendix as a sign of acute appendicitis: evaluation at US. Radiology 2001; 218: 757 - 762. doi:10.1148/radiology.218.3. r01fe20757

[28] Jeffrey RB Jr, Laing FC, Townsend RR. Acute appendicitis: sonographic criteria based on 250 cases. Radiology 1988; 167: 327 - 329. doi:10.1148/radiology.167.2.3282253

[29] Birnbaum BA, Jeffrey RB Jr. CT and sonographic evaluation of acute right lower quadrant abdominal pain. Am J Roentgenol 1998; 170: 361 - 371. doi:10.2214/ajr.170.2.9456947

[30] Summa M, Perrone F, Priora F et al. Integrated clinical-ultrasonographic diagnosis in acute appendicitis. J Ultrasound 2007; 10: 175 - 178. doi:10.1016/j.jus.2007.09.004

[31] Trout AT, Towbin AJ, Fierke SR et al. Appendiceal diameter as a predictor of appendicitis in children: improved diagnosis with three diagnostic categories derived from a logistic predictive model. Eur Radiol 2015; 25 : 2231 - 2238. doi:10.1007/s00330-015-3639-x 
[32] Chicaiza HP, Malia L, Mulvey CH et al. Revisiting the Appendiceal Diameter via Ultrasound for the Diagnosis of Acute Appendicitis. Pediatric emergency care 2017. doi:10.1097/pec.0000000000001278

[33] Lee JH, Jeong YK, Hwang JC et al. Graded compression sonography with adjuvant use of a posterior manual compression technique in the sonographic diagnosis of acute appendicitis. Am J Roentgenol 2002; 178: 863 - 868. doi:10.2214/ajr.178.4.1780863

[34] Rettenbacher T, Hollerweger A, Macheiner P et al. Presence or absence of gas in the appendix: additional criteria to rule out or confirm acute appendicitis-evaluation with US. Radiology 2000; 214: 183-187. doi:10.1148/radiology.214.1.r00ja20183

[35] Rettenbacher T, Hollerweger A, Macheiner P et al. Ovoid shape of the vermiform appendix: a criterion to exclude acute appendicitis-evaluation with US. Radiology 2003; 226: 95 -100. doi:10.1148/radiol.2261011496

[36] Telesmanich ME, Orth RC, Zhang W et al. Searching for certainty: findings predictive of appendicitis in equivocal ultrasound exams. Pediatr Radiol 2016; 46: 1539-1545. doi:10.1007/s00247-016-3645-4

[37] Lim HK, Lee W], Kim TH et al. Appendicitis: usefulness of color Doppler US. Radiology 1996; 201: 221-225. doi:10.1148/radiology.201.1.8816547

[38] Xu Y, Jeffrey RB, Shin LK et al. Color Doppler Imaging of the Appendix: Criteria to Improve Specificity for Appendicitis in the Borderline-Size Appendix. J Ultrasound Med 2016; 35: 2129-2138. doi:10.7863/ ultra.15.11064

[39] Tulin-Silver S, Babb J, Pinkney L et al. The challenging ultrasound diagnosis of perforated appendicitis in children: constellations of sonographic findings improve specificity. Pediatr Radiol 2015; 45: 820-830. doi:10.1007/s00247-014-3232-5

[40] Dietrich CF, Lembcke B, Jenssen C et al. Intestinal ultrasound in rare gastrointestinal diseases, update, part 1. Ultraschall in Med 2014; 35 : 400-421. doi:10.1055/s-0034-1385154

[41] Dietrich CF, Lembcke B, Jenssen C et al. Intestinal Ultrasound in Rare Gastrointestinal Diseases, Update, Part 2. Ultraschall in Med 2015; 36: 428 - 456. doi:10.1055/s-0034-1399730

[42] Carpenter JL, Orth RC, Zhang W et al. Diagnostic Performance of US for Differentiating Perforated from Nonperforated Pediatric Appendicitis: A Prospective Cohort Study. Radiology 2017; 282: 835 - 841. doi:10.1148/ radiol.2016160175

[43] Blumfield E, Yang D, Grossman J. Scoring system for differentiating perforated and non-perforated pediatric appendicitis. Emerg Radiol 2017; 24: 547 - 554. doi:10.1007/s10140-017-1535-1

[44] Avanesov M, Wiese N], Karul M et al. Diagnostic prediction of complicated appendicitis by combined clinical and radiological appendicitis severity index (APSI). Eur Radiol 2018. doi:10.1007/s00330-018-5339-9

[45] Kim HY, Park JH, Lee Y] et al. Systematic Review and Meta-Analysis of CT Features for Differentiating Complicated and Uncomplicated Appendicitis. Radiology 2018; 287: 104-115. doi:10.1148/radiol.2017171260

[46] Gomes CA, Sartelli M, Di Saverio S et al. Acute appendicitis: proposal of a new comprehensive grading system based on clinical, imaging and laparoscopic findings. World J Emerg Surg 2015; 10: 60. doi:10.1186/ s13017-015-0053-2

[47] Huang L, Yin Y, Yang L et al. Comparison of Antibiotic Therapy and Appendectomy for Acute Uncomplicated Appendicitis in Children: A Meta-analysis. JAMA Pediatr 2017; 171: 426-434. doi:10.1001/jamapediatrics.2017.0057

[48] Mahida JB, Lodwick DL, Nacion KM et al. High failure rate of nonoperative management of acute appendicitis with an appendicolith in children. J Pediatr Surg 2016; 51: 908 - 911. doi:10.1016/j.jpedsurg.2016.02.056

[49] Wiersma F, Toorenvliet BR, Bloem JL et al. US examination of the appendix in children with suspected appendicitis: the additional value of secondary signs. Eur Radiol 2009; 19: 455 - 461. doi:10.1007/s00330-0081176-6
[50] Estey A, Poonai N, Lim R. Appendix not seen: the predictive value of secondary inflammatory sonographic signs. Pediatric emergency care 2013; 29: 435 - 439. doi:10.1097/PEC.0b013e318289e8d5

[51] Partain KN, Patel A, Travers C et al. Secondary signs may improve the diagnostic accuracy of equivocal ultrasounds for suspected appendicitis in children. Journal of pediatric surgery 2016; 51: 1655-1660. doi:10.1016/j.jpedsurg.2016.03.005

[52] Damani N, Wilson SR. Nongynecologic applications of transvaginal US. Radiographics: a review publication of the Radiological Society of North America, Inc 1999. 19 Spec No: S179-200; quiz S265-176. doi:10.1148/ radiographics.19.suppl_1.g99oc15s179

[53] Lin W, Jeffrey RB, Trinh A et al. Anatomic Reasons for Failure to Visualize the Appendix With Graded Compression Sonography: Insights From Contemporaneous CT. Am J Roentgenol 2017; 209: W128 -W138. doi:10.2214/Am J Roentgenol.17.18059

[54] Hollerweger A. Sonographie der akuten Appendizitis. Ultraschall in der Medizin - European Journal of Ultrasound 2006; 27: 412-432. doi:10.1055/s-2006-927118

[55] Poljak A, Jeffrey RB Jr, Kernberg ME. The gas-containing appendix: potential sonographic pitfall in the diagnosis of acute appendicitis. J Ultrasound Med 1991; 10: 625-628

[56] Cobben LP, de Van Otterloo AM, Puylaert JB. Spontaneously resolving appendicitis: frequency and natural history in 60 patients. Radiology 2000; 215: 349-352. doi:10.1148/radiology.215.2.r00ma08349

[57] Migraine S, Atri M, Bret PM et al. Spontaneously resolving acute appendicitis: clinical and sonographic documentation. Radiology 1997; 205: 55-58. doi:10.1148/radiology.205.1.9314962

[58] Andersson RE. The natural history and traditional management of appendicitis revisited: spontaneous resolution and predominance of prehospital perforations imply that a correct diagnosis is more important than an early diagnosis. World J Surg 2007; 31: 86-92. doi:10.1007| s00268-006-0056-y

[59] Kwon LM, Lee K, Min SK et al. Ultrasound features of secondary appendicitis in pediatric patients. Ultrasonography (Seoul, Korea) 2017. doi: $10.14366 /$ usg. 17029

[60] Puylaert JB. Mesenteric adenitis and acute terminal ileitis: US evaluation using graded compression. Radiology 1986; 161: 691-695. doi:10.1148/radiology.161.3.3538138

[61] Puylaert JB. Ultrasound of appendicitis and its differential diagnosis. Berlin: Springer-Verlag; 1990

[62] Jeffrey RB, Jain KA, Nghiem HV. Sonographic diagnosis of acute appendicitis: interpretive pitfalls. Am J Roentgenol 1994; 162: 55 - 59. doi:10.2214/ajr.162.1.8273690

[63] Swischuk LE, John SD. Mesenteric adenitis-acute ileitis: a constellation of findings definable with ultrasound. Emerg Radiol 1998; 5: 210-218

[64] van Breda Vriesman AC, Puylaert JB. Mimics of appendicitis: alternative nonsurgical diagnoses with sonography and CT. Am J Roentgenol 2006; 186: 1103 - 1112. doi:10.2214/Am J Roentgenol.05.0085

[65] Puylaert JB, van der Werf SD, Ulrich C et al. Crohn disease of the ileocecal region: US visualization of the appendix. Radiology 1988; 166: 741 743. doi:10.1148/radiology.166.3.3277243

[66] Ripolles T, Martinez-Perez M], Morote $V$ et al. Diseases that simulate acute appendicitis on ultrasound. The British journal of radiology 1998; 71: 94 - 98. doi:10.1259/bjr.71.841.9534708

[67] Ripolles T, Martinez M], Morote $V$ et al. Appendiceal involvement in Crohn's disease: gray-scale sonography and color Doppler flow features. Am J Roentgenol 2006; 186: 1071 - 1078. doi:10.2214/Am J Roentgenol.04.1839

[68] Becking WB, Puylaert JB, Feldberg MA et al. Appendiceal involvement in cecal carcinoma: demonstration by ultrasound. Gastrointestinal radiology 1989; 14: 170-172 
[69] Rioux M, Duchesne N, Langis P. Carcinoid tumor of the appendix: ultrasound findings in two cases. J Clin Ultrasound 1994; 22: 129-133

[70] Ripolles T, Concepcion L, Martinez-Perez M] et al. Appendicular involvement in perforated sigmoid disease: US and CT findings. Eur Radiol 1999; 9: 697 - 700. doi:10.1007/s003300050735

[71] Simonovsky V. Ultrasound in the differential diagnosis of appendicitis. Clinical radiology 1995; 50: 768-773

[72] Dahabreh I], Adam GP, Halladay CW et al. AHRQ Comparative Effectiveness Reviews. In Diagnosis of Right Lower Quadrant Pain and Suspected Acute Appendicitis. Rockville (MD): Agency for Healthcare Research and Quality (US). 2015

[73] Benabbas R, Hanna M, Shah J et al. Diagnostic Accuracy of History, Physical Examination, Laboratory Tests, and Point-of-care Ultrasound for Pediatric Acute Appendicitis in the Emergency Department: A Systematic Review and Meta-analysis. Academic emergency medicine: official journal of the Society for Academic Emergency Medicine 2017; 24: 523 - 551. doi:10.1111/acem. 13181

[74] Repplinger MD, Levy JF, Peethumnongsin E et al. Systematic review and meta-analysis of the accuracy of MRI to diagnose appendicitis in the general population. Journal of magnetic resonance imaging: JMRI 2016; 43: 1346 - 1354. doi:10.1002/jmri.25115

[75] Cundy TP, Gent R, Frauenfelder C et al. Benchmarking the value of ultrasound for acute appendicitis in children. Journal of pediatric surgery 2016; 51: 1939-1943. doi:10.1016/j.jpedsurg.2016.09.009

[76] Dibble EH, Swenson DW, Cartagena C et al. Effectiveness of a Staged US and Unenhanced MR Imaging Algorithm in the Diagnosis of Pediatric Appendicitis. Radiology 2017. doi:10.1148/radiol.2017162755

[77] Fallon SC, Orth RC, Guillerman RP et al. Development and validation of an ultrasound scoring system for children with suspected acute appendicitis. Pediatr Radiol 2015; 45: 1945 - 1952. doi:10.1007/s00247-0153443-4

[78] Zhang $\mathrm{H}$, Liao M, Chen J et al. Ultrasound, computed tomography or magnetic resonance imaging - which is preferred for acute appendicitis in children? A Meta-analysis. Pediatr Radiol 2017; 47: 186-196. doi:10.1007/s00247-016-3727-3

[79] Lofvenberg F, Salo M. Ultrasound for Appendicitis: Performance and Integration with Clinical Parameters. BioMed research international 2016; 2016: 5697692. doi:10.1155/2016/5697692

[80] Mittal MK, Dayan PS, Macias CG et al. Performance of ultrasound in the diagnosis of appendicitis in children in a multicenter cohort. Academic emergency medicine: official journal of the Society for Academic Emergency Medicine 2013; 20: 697 - 702. doi:10.1111/acem.12161

[81] Lembcke B. Ultrasonography for acute appendicitis - the way it looks today. Zeitschrift fur Gastroenterologie 2016; 54: 1151 - 1165. doi:10.1055/s-0042-116949

[82] Keller C, Wang NE, Imler DL et al. Predictors of Nondiagnostic Ultrasound for Appendicitis. The Journal of emergency medicine 2017; 52: 318-323. doi:10.1016/j.jemermed.2016.07.101

[83] Matthew Fields J, Davis J, Alsup C et al. Accuracy of Point-of-care Ultrasonography for Diagnosing Acute Appendicitis: A Systematic Review and Meta-analysis. Academic emergency medicine: official journal of the Society for Academic Emergency Medicine 2017; 24: 1124-1136. doi:10.1111/acem.13212

[84] Beltzer CR, Zischek C, Schmidt R et al. The Relevance of Surgeon-performed Ultrasound For the Detection of Acute Appendicitis: a Review of the Literature and a Practical Diagnostic Algorithm. Zentralblatt fur Chirurgie 2017; 142: 395-403. doi:10.1055/s-0043-114414

[85] Gungor F, Kilic T, Akyol KC et al. Diagnostic Value and Effect of Bedside Ultrasound in Acute Appendicitis in the Emergency Department. Academic emergency medicine: official journal of the Society for Academic Emergency Medicine 2017; 24: 578-586. doi:10.1111/acem.13169
[86] Dietrich CF, Goudie A, Chiorean L et al. Point of Care Ultrasound: A WFUMB Position Paper. Ultrasound in medicine \& biology 2017; 43: 49 58. doi:10.1016/j.ultrasmedbio.2016.06.021

[87] Di Saverio S, Birindelli A, Kelly MD et al. WSES Jerusalem guidelines for diagnosis and treatment of acute appendicitis. World J Emerg Surg 2016; 11: 34. doi:10.1186/s13017-016-0090-5

[88] Parker L, Nazarian LN, Gingold EL et al. Cost and radiation savings of partial substitution of ultrasound for CT in appendicitis evaluation: a national projection. Am J Roentgenol 2014; 202: 124-135. doi:10.2214/Am J Roentgenol.12.9642

[89] Mostbeck G, Adam EJ, Nielsen MB et al. How to diagnose acute appendicitis: ultrasound first. Insights Imaging 2016; 7: 255-263. doi:10.1007/s13244-016-0469-6

[90] Debnath J, George RA, Ravikumar R. Imaging in acute appendicitis: What, when, and why? Med J Armed Forces India 2017; 73: 74-79. doi:10.1016/j.mjafi.2016.02.005

[91] Rettenbacher T, Hollerweger A, Gritzmann N et al. Appendicitis: Should diagnostic imaging be performed if the clinical presentation is highly suggestive of the disease? Gastroenterology 2002; 123: 992 - 998. doi:10.1053/gast.2002.35956

[92] van Rossem CC, Bolmers MD, Schreinemacher MH et al. Prospective nationwide outcome audit of surgery for suspected acute appendicitis. The British journal of surgery 2016; 103: 144-151. doi:10.1002/bjs.9964

[93] Bolmers MD, van Rossem CC, Gorter RR et al. Imaging in pediatric appendicitis is key to a low normal appendix percentage: a national audit on the outcome of appendectomy for appendicitis in children. Pediatr Surg Int 2018; 34: 543 - 551. doi:10.1007/s00383-018-4244-2

[94] Krishnamoorthi R, Ramarajan N, Wang NE et al. Effectiveness of a staged US and CT protocol for the diagnosis of pediatric appendicitis: reducing radiation exposure in the age of ALARA. Radiology 2011; 259: 231 - 239. doi:10.1148/radiol.10100984

[95] Kotagal M, Richards MK, Flum DR et al. Use and accuracy of diagnostic imaging in the evaluation of pediatric appendicitis. Journal of pediatric surgery 2015; 50: 642 -646. doi:10.1016/j.jpedsurg.2014.09.080

[96] Atema JJ, Gans SL, Van Randen A et al. Comparison of Imaging Strategies with Conditional versus Immediate Contrast-Enhanced Computed Tomography in Patients with Clinical Suspicion of Acute Appendicitis. Eur Radiol 2015; 25: 2445 - 2452. doi:10.1007/s00330-015-3648-9

[97] Ramarajan N, Krishnamoorthi R, Barth R et al. An interdisciplinary initiative to reduce radiation exposure: evaluation of appendicitis in a pediatric emergency department with clinical assessment supported by a staged ultrasound and computed tomography pathway. Academic emergency medicine: official journal of the Society for Academic Emergency Medicine 2009; 16: 1258 - 1265. doi:10.1111/j.1553-2712.2009.00511.x

[98] Kotagal M, Richards MK, Chapman T et al. Improving ultrasound quality to reduce computed tomography use in pediatric appendicitis: the Safe and Sound campaign. American journal of surgery 2015; 209: 896-900; discussion 900. doi:10.1016/j.amjsurg.2014.12.029

[99] Leeuwenburgh MM, Lameris W, van Randen A et al. Optimizing imaging in suspected appendicitis (OPTIMAP-study): a multicenter diagnostic accuracy study of MRI in patients with suspected acute appendicitis. Study Protocol. BMC Emerg Med 2010; 10: 19. doi:10.1186/1471-227X-10-19

[100] Reuvers JR, Rijbroek AA. Acute appendicitis: preference for second ultrasound instead of CT or MRI. Nederlands tijdschrift voor geneeskunde 2015; 160: A9480

[101] Schuh S, Chan K, Langer JC et al. Properties of serial ultrasound clinica diagnostic pathway in suspected appendicitis and related computed tomography use. Academic emergency medicine: official journal of the Society for Academic Emergency Medicine 2015; 22: 406 - 414. doi:10.1111/acem. 12631

[102] Gorter RR, Eker HH, Gorter-Stam MA et al. Diagnosis and management of acute appendicitis. EAES consensus development conference 2015. Surg Endosc 2016; 30: 4668 - 4690. doi:10.1007/s00464-016-5245-7 
[103] Ohle R, O'Reilly F, O'Brien KK et al. The Alvarado score for predicting acute appendicitis: a systematic review. BMC medicine 2011; 9: 139. doi:10.1186/1741-7015-9-139

[104] Sammalkorpi HE, Leppaniemi A, Lantto E et al. Performance of imaging studies in patients with suspected appendicitis after stratification with adult appendicitis score. World J Emerg Surg 2017; 12: 6. doi:10.1186/ s13017-017-0119-4

[105] Ebell MH, Shinholser J. What are the most clinically useful cutoffs for the Alvarado and Pediatric Appendicitis Scores? A systematic review. Annals of emergency medicine 2014; 64: 365 -372.e362. doi:10.1016/j.annemergmed.2014.02.025

[106] Alter SM, Walsh B, Lenehan PJ et al. Ultrasound for Diagnosis of Appendicitis in a Community Hospital Emergency Department has a High Rate of Nondiagnostic Studies. The Journal of emergency medicine 2017; 52: 833-838. doi:10.1016/j.jemermed.2017.01.003

[107] Cohen B, Bowling J, Midulla P et al. The non-diagnostic ultrasound in appendicitis: is a non-visualized appendix the same as a negative study? Journal of pediatric surgery 2015; 50: 923 -927. doi:10.1016/ j.jpedsurg.2015.03.012

[108] Larson DB, Trout AT, Fierke SR et al. Improvement in diagnostic accuracy of ultrasound of the pediatric appendix through the use of equivocal interpretive categories. Am J Roentgenol 2015; 204: 849- 856. doi:10.2214/Am J Roentgenol.14.13026

[109] Topin F, Thierry AL, Catrevaux O et al. Diagnostic Accuracy of Emergency Physician-Performed Ultrasound for Acute Appendicitis in a Remote Location. The Journal of emergency medicine 2016; 50: 859867. doi:10.1016/j.jemermed.2015.06.085

[110] Carroll PJ, Gibson D, El-Faedy O et al. Surgeon-performed ultrasound at the bedside for the detection of appendicitis and gallstones: systematic review and meta-analysis. Am J Surg 2013; 205: 102 - 108. doi:10.1016/j.amjsurg.2012.02.017

[111] Fox JC, Solley M, Anderson CL et al. Prospective evaluation of emergency physician performed bedside ultrasound to detect acute appendicitis. European journal of emergency medicine: official journal of the European Society for Emergency Medicine 2008; 15: 80 - 85. doi:10.1097/MEJ.0b013e328270361a

[112] Kim J, Kim K, Kim J et al. The learning curve in diagnosing acute appendicitis with emergency sonography among novice emergency medicine residents. J Clin Ultrasound 2018. doi:10.1002/jcu.22577

[113] Nielsen JW, Boomer L, Kurtovic K et al. Reducing computed tomography scans for appendicitis by introduction of a standardized and validated ultrasonography report template. Journal of pediatric surgery 2015; 50: 144 -148. doi:10.1016/j.jpedsurg.2014.10.033

[114] Partain KN, Patel AU, Travers C et al. Improving ultrasound for appendicitis through standardized reporting of secondary signs. Journal of pediatric surgery 2017; 52: 1273-1279. doi:10.1016/j.jpedsurg.2016.11.045

[115] Anderson KT, Bartz-Kurycki M, Austin MT et al. Approaching zero: Implications of a computed tomography reduction program for pediatric appendicitis evaluation. Journal of pediatric surgery 2017; 52: 1909 1915. doi:10.1016/j.jpedsurg.2017.08.050

[116] Godwin BD, Simianu VV, Drake FT et al. Is there a need to standardize reporting terminology in appendicitis? Ultrasound Q 2015; 31: 92 - 94. doi:10.1097/RUQ.0000000000000123

[117] Atkinson NSS, Bryant RV, Dong Y et al. How to perform gastrointestinal ultrasound: Anatomy and normal findings. World J Gastroenterol 2017; 23: 6931-6941. doi:10.3748/wjg.v23.i38.6931

[118] Atkinson NS, Bryant RV, Dong Y et al. WFUMB Position Paper. Learning Gastrointestinal Ultrasound: Theory and Practice. Ultrasound Med Biol 2016; 42: 2732 -2742. doi:10.1016/j.ultrasmedbio.2016.08.026

[119] Wheat CL, Strate LL. Trends in Hospitalization for Diverticulitis and Diverticular Bleeding in the United States From 2000 to 2010. Clin
Gastroenterol Hepatol 2016; 14: 96 - 103 e101. doi:10.1016/ j.cgh.2015.03.030

[120] Peery AF, Barrett PR, Park D et al. A high-fiber diet does not protect against asymptomatic diverticulosis. Gastroenterology 2012; 142: 266-272 e261. doi:10.1053/j.gastro.2011.10.035

[121] Loffeld RJ. Long-term follow-up and development of diverticulitis in patients diagnosed with diverticulosis of the colon. Int J Colorectal Dis 2016; 31: 15-17. doi:10.1007/s00384-015-2397-1

[122] Andeweg CS, Knobben L, Hendriks JC et al. How to diagnose acute leftsided colonic diverticulitis: proposal for a clinical scoring system. Ann Surg 2011; 253: 940 - 946. doi:10.1097/SLA.0b013e3182113614

[123] Lameris W, van Randen A, van Gulik TM et al. A clinical decision rule to establish the diagnosis of acute diverticulitis at the emergency department. Dis Colon Rectum 2010; 53: 896-904. doi:10.1007| DCR.0b013e3181d98d86

[124] Sartelli M, Catena F, Ansaloni L et al. WSES Guidelines for the management of acute left sided colonic diverticulitis in the emergency setting. World J Emerg Surg 2016; 11: 37. doi:10.1186/s13017-016-0095-0

[125] Leifeld L, Germer CT, Bohm S et al. S2k guidelines diverticular disease/ diverticulitis. Zeitschrift fur Gastroenterologie 2014; 52: 663 - 710. doi:10.1055/s-0034-1366692

[126] Andeweg CS, Mulder IM, Felt-Bersma RJ et al. Guidelines of diagnostics and treatment of acute left-sided colonic diverticulitis. Digestive surgery 2013; 30: 278 -292. doi:10.1159/000354035

[127] Boermeester MA, Humes DJ, Velmahos GC et al. Contemporary Review of Risk-Stratified Management in Acute Uncomplicated and Complicated Diverticulitis. World journal of surgery 2016; 40: $2537-2545$. doi:10.1007/s00268-016-3560-8

[128] Galetin T, Galetin A, Vestweber KH et al. Systematic review and comparison of national and international guidelines on diverticular disease. Int J Colorectal Dis 2018; 33: 261 - 272. doi:10.1007/s00384-017-2960-z

[129] Hollerweger A, Macheiner P, Gritzmann N. Acute left lower quadrant abdominal pain: ultrasonographic differential diagnosis. Ultraschall in Med 2003; 24: 7-16. doi:10.1055/s-2003-37410

[130] Puylaert JB. Ultrasound of colon diverticulitis. Dig Dis 2012; 30: 56 59. doi:10.1159/000336620

[131] Klarenbeek BR, de Korte N, van der Peet DL et al. Review of current classifications for diverticular disease and a translation into clinical practice. International journal of colorectal disease 2012; 27: 207 214. doi:10.1007/s00384-011-1314-5

[132] Hughes ES, Cuthbertson AM, Carden AB. The surgical management of acute diverticulitis. The Medical journal of Australia 1963; 50: 780 - 782

[133] Hinchey El, Schaal PG, Richards GK. Treatment of perforated diverticular disease of the colon. Advances in surgery 1978; 12: 85-109

[134] Ambrosetti P, Becker C, Terrier F. Colonic diverticulitis: impact of imaging on surgical management - a prospective study of 542 patients. Eur Radiol 2002; 12: 1145 - 1149. doi:10.1007/s00330-001-1143-y

[135] Schwerk WB, Schwarz S, Rothmund M. Sonography in acute colonic diverticulitis. A prospective study. Diseases of the colon and rectum 1992; 35: $1077-1084$

[136] Hollerweger A, Macheiner P, Rettenbacher T et al. Colonic diverticulitis: diagnostic value and appearance of inflamed diverticula-sonographic evaluation. Eur Radiol 2001; 11: 1956 - 1963. doi:10.1007/ s003300100942

[137] Lembcke B. Diagnosis, Differential Diagnoses, and Classification of Diverticular Disease. Viszeralmedizin 2015; 31: 95 - 102. doi:10.1159/ 000380833

[138] Pustelnik D, Elsholtz FHJ, Bojarski C et al. The CDD System in Computed Tomographic Diagnosis of Diverticular Disease. Rofo 2017; 189: 740-747. doi:10.1055/s-0043-110770

[139] Maconi G, Carmagnola S, Guzowski T. Intestinal Ultrasonography in the Diagnosis and Management of Colonic Diverticular Disease. Jour- 
nal of clinical gastroenterology 2016; 50 (Suppl. 1): S20 - S22. doi:10.1097/mcg.0000000000000657

[140] Valentino M, Serra C, Ansaloni L et al. Sonographic features of acute colonic diverticulitis. Journal of clinical ultrasound: JCU 2009; 37 : 457 463. doi:10.1002/jcu.20619

[141] Hollerweger A, Dirks K, Szopinski K. Transabdominal ultrasound of the gastrointestinal tract. In: Dietrich CF, ed; EFSUMB - European Course Book. EFSUMB; 2015: 1 - 56

[142] Lameris W, van Randen A, Bipat S et al. Graded compression ultrasonography and computed tomography in acute colonic diverticulitis: meta-analysis of test accuracy. Eur Radiol 2008; 18: 2498-2511. doi:10.1007/s00330-008-1018-6

[143] Liljegren G, Chabok A, Wickbom M et al. Acute colonic diverticulitis: a systematic review of diagnostic accuracy. Colorectal disease: the official journal of the Association of Coloproctology of Great Britain and Ireland 2007; 9: 480 - 488. doi:10.1111/j.1463-1318.2007.01238.x

[144] Andeweg CS, Wegdam JA, Groenewoud J et al. Toward an evidencebased step-up approach in diagnosing diverticulitis. Scandinavian journal of gastroenterology 2014; 49: 775 - 784. doi:10.3109/ 00365521.2014 .908475

[145] Farag Soliman M, Wustner M, Sturm J et al. Primary diagnostics of acute diverticulitis of the sigmoid. Ultraschall in Med 2004; 25 : 342 347. doi:10.1055/s-2004-813381

[146] Cuomo R, Barbara G, Pace F et al. Italian consensus conference for colonic diverticulosis and diverticular disease. United European gastroenterology journal 2014; 2: 413 -442. doi:10.1177/ 2050640614547068

[147] Helou N, Abdalkader M, Abu-Rustum RS. Sonography: first-line modality in the diagnosis of acute colonic diverticulitis? J Ultrasound Med 2013; 32: 1689 - 1694. doi:10.7863/ultra.32.10.1689

[148] King WC, Shuaib W, Vijayasarathi A et al. Benefits of sonography in diagnosing suspected uncomplicated acute diverticulitis. J Ultrasound Med 2015; 34: 53 - 58. doi:10.7863/ultra.34.1.53

[149] Andersen JC, Bundgaard L, Elbrond $\mathrm{H}$ et al. Danish national guidelines for treatment of diverticular disease. Danish medical journal 2012; 59: C4453

[150] Flor N, Maconi G, Cornalba G et al. The Current Role of Radiologic and Endoscopic Imaging in the Diagnosis and Follow-Up of Colonic Diverticular Disease. Am J Roentgenol 2016; 207: 15 - 24. doi:10.2214/ ajr. 16.16138

[151] Onur MR, Akpinar E, Karaosmanoglu AD et al. Diverticulitis: a comprehensive review with usual and unusual complications. Insights Imaging 2017; 8: 19-27. doi:10.1007/s13244-016-0532-3

[152] Ripolles T, Martinez-Perez M], Paredes JM et al. Contrast-enhanced ultrasound in the differentiation between phlegmon and abscess in Crohn's disease and other abdominal conditions. European journal of radiology 2013; 82: e525 - 531. doi:10.1016/j.ejrad.2013.05.043

[153] Nurnberg D, Mauch M, Spengler ] et al. Sonographical diagnosis of pneumoretroperitoneum as a result of retroperitoneal perforation. Ultraschall in Med 2007; 28: 612 -621. doi:10.1055/s-2007-963216

[154] Chou YH, Chiou HJ, Tiu CM et al. Sonography of acute right side colonic diverticulitis. American journal of surgery 2001; 181: 122-127

[155] Hollerweger A, Rettenbacher T, Macheiner P et al. Sigmoid diverticulitis: value of transrectal sonography in addition to transabdominal sonography. Am J Roentgenol 2000; 175: 1155 - 1160. doi:10.2214/ ajr.175.4.1751155

[156] Schiller VL, Schreiber L, Seaton C et al. Transvaginal sonographic diagnosis of sigmoid diverticulitis. Abdom Imaging 1995; 20: 253 - 255

[157] Claudon M, Dietrich CF, Choi BI et al. Guidelines and good clinical practice recommendations for Contrast Enhanced Ultrasound (CEUS) in the liver - update 2012: A WFUMB-EFSUMB initiative in cooperation with representatives of AFSUMB, AIUM, ASUM, FLAUS and ICUS. Ultra- sound in medicine \& biology 2013; 39: 187 - 210. doi:10.1016/ j.ultrasmedbio.2012.09.002

[158] Dietrich CF, Lorentzen T, Appelbaum L et al. EFSUMB Guidelines on Interventional Ultrasound (INVUS), Part III - Abdominal Treatment Procedures (Long Version). Ultraschall in Med 2016; 37: E1 - E32. doi:10.1055/s-0035-1553917

[159] Ignee A, Jenssen C, Cui XW et al. Intracavitary contrast-enhanced ultrasound in abscess drainage-feasibility and clinical value. Scandinavian journal of gastroenterology 2016; 51: 41 -47. doi:10.3109/ 00365521.2015 .1066423

[160] Gregersen R, Mortensen LQ, Burcharth J et al. Treatment of patients with acute colonic diverticulitis complicated by abscess formation: A systematic review. Int J Surg 2016; 35: 201 -208. doi:10.1016/ j.ijsu.2016.10.006

[161] Siewert B, Tye G, Kruskal J et al. Impact of CT-guided drainage in the treatment of diverticular abscesses: size matters. Am J Roentgeno 2006; 186: 680 -686. doi:10.2214/Am J Roentgenol.04.1708

[162] Guidelines WGOP. World Gastroenterology Organisation Guideline 2007. 2007

[163] Cai YL, Xiong XZ, Lu J et al. Percutaneous needle aspiration versus catheter drainage in the management of liver abscess: a systematic review and meta-analysis. HPB: the official journal of the International Hepato Pancreato Biliary Association 2015; 17: 195 - 201. doi:10.1111/hpb.12332

[164] Lorentzen T, Nolsoe C, Skjoldbye B. Ultrasound-guided drainage of deep pelvic abscesses: experience with 33 cases. Ultrasound Med Biol 2011; 37: 723 - 728. doi:10.1016/j.ultrasmedbio.2011.02.004

[165] Brandt D, Gervaz P, Durmishi Y et al. Percutaneous CT scan-guided drainage vs. antibiotherapy alone for Hinchey II diverticulitis: a casecontrol study. Diseases of the colon and rectum 2006; 49: 1533 1538. doi:10.1007/s10350-006-0613-3

[166] Ignee A, Schuessler G, Cui XW et al. Intracavitary contrast medium ultrasound - different applications, a review of the literature ad future prospects. Ultraschall in Med 2013; 34: 504 - 525; quiz 526-508. doi:10.1055/s-0033-1335546

[167] Ritz JP, Lehmann KS, Loddenkemper C et al. Preoperative CT staging in sigmoid diverticulitis-does it correlate with intraoperative and histological findings? Langenbecks Arch Surg 2010; 395: 1009-1015. doi:10.1007/s00423-010-0609-2

[168] Gielens MP, Mulder IM, van der Harst E et al. Preoperative staging of perforated diverticulitis by computed tomography scanning. Techniques in coloproctology 2012; 16: 363 - 368. doi:10.1007/s10151012-0853-2

[169] van Randen A, Lameris W, van Es HW et al. A comparison of the accuracy of ultrasound and computed tomography in common diagnoses causing acute abdominal pain. Eur Radiol 2011; 21: 1535-1545. doi:10.1007/s00330-011-2087-5

[170] Caputo P, Rovagnati M, Carzaniga PL. Is it possible to limit the use of CT scanning in acute diverticular disease without compromising outcomes? A preliminary experience. Annali italiani di chirurgia 2015; 86: 51 - 55

[171] van Dijk ST, Bos K, de Boer MG] et al. A systematic review and metaanalysis of outpatient treatment for acute diverticulitis. Int J Colorectal Dis 2018; 33: 505 - 512. doi:10.1007/s00384-018-3015-9

[172] Lembcke B. Ultrasonography in acute diverticulitis - credit where credit is due. Zeitschrift fur Gastroenterologie 2016; 54: 47 - 57. doi:10.1055/s-0041-108204

[173] Lameris W, van Randen A, van Es HW et al. Imaging strategies for detection of urgent conditions in patients with acute abdominal pain: diagnostic accuracy study. Bmj 2009; 338: b2431. doi:10.1136/bmj.b2431

[174] Lembcke BJ, Strobel D, Dirks K et al. Statement of the section internal medicine of the DEGUM - ultrasound obtains pole position for clinical imaging in acute diverticulitis. Ultraschall in Med 2015; 36: 191 - 195 